\section{Leadership needed}

SIR - Your recent leading article ( $\mathrm{Na}$ ture 353, 285; 1991) in favour of a stronger Non-Proliferation Treaty (NPT) addressed principally the behaviour of Iraq, one of the earliest signatories, yet a country now known to have had a major clandestine programme of nuclear weapons development. But there is a stumbling block to continuation - let alone to a stronger treaty. A Comprehensive Test Ban Treaty (CTBT) is viewed by many non-nuclear-weapon states as a sine qua non for preserving the NPT regime, yet the United States and the United Kingdom refuse to com mit themselves to near-term pursuit of such an accord. For example, the Bush Administration asserted in 1990 that: "The United States has not identified any further limitations on nuclear testing beyond those now contained in the TTBT [the Threshold Test Ban Treaty, banning all underground weapons tests with yield greater than 150 kilotons] that would be in the US national security interest."

A conference is to be convened in 1995 to decide (by majority vote of all countries that signed the NPT) whether the NPT "shall continue in force indefinitely, or shall be extended for an additional fixed period or periods". One proposal, supported by the United States and the Soviet Union, called for a preparatory meeting (to the NPT extension conference) no earlier than 1993. But Mexico, and like-minded countries pursuing a CTBT first, want a much earlier preparatory meeting. Their point is that non-nuclear-weapon states should not agree to preservation of horizontal nonproliferation (preventing the spread of nuclear weapons technology to new countries) unless the present nuclearcapable states make progress on vertical nonproliferation (preventing the development of more sophisticated nuclear weapons).

Progress in strengthening the NPT will surely be linked to restrictions on nuclear weapons development by the United States and the United Kingdom. The Soviet Union has long stated the need for such restrictions, and has recently announced a new unilateral moratorium on nuclear testing.

If a CTBT is not acceptable in Washington and London, then serious consideration must be given to limitations on nuclear weapon testing that are less stringent than a comprehensive ban. An obvious solution would be multilateral agreement on a new threshold, much lower than the present (bilateral USUSSR) 150-kiloton limit. Consideration of such a new limitation would be a mark of political leadership, desperately needed if policy for the world is not to be set by those who profit from current styles of nuclear testing and nuclear proliferation.

\section{amont-Doherty Geologi of Columbia University,}

Palisades, New York 10964, USA

\section{Pseudo-dilemma?}

SIR - Grünbaum argues ${ }^{1}$ that even if we assume that $t_{0}$ is a well-defined instant at which the Big Bang singularity occurred, that 'event' cannot "have any cause at all in the Universe" (presumably because backward causation is impossible) nor can it "be the effect of any prior cause" (because time did not exist before $t_{0}$ ). Therefore, the initial cosmological singularity must be uniquely uncaused, and the question of what caused the Universe's origin is therefore a "pseudoproblem".

Unfortunately, Grünbaum's objection is pretty clearly a pseudo-dilemma. For he fails to consider the obvious alternative that the cause of the Big Bang operated at $t_{0}$, simultaneously with the Big Bang. Philosophical discussions of causal directionality routinely treat simultaneous causation, the question being how to distinguish $\mathrm{A}$ as the cause and $B$ as the effect when these occur together at the same time. There seems to be no conceptual difficulty in saying that the cause of the origin of the Universe is causally, though not temporally, before the Big Bang and acted simultaneously (or coincidentally) with the origination of the Universe. From the nature of the case involved, the cause must have existed spacelessly and timelessly sans the Universe and entered into time at the moment of creation.

But why think that such a cause exists at all? The causal inference is based in the metaphysical intuition that something cannot come out of absolutely nothing. On the theistic hypothesis, the potentiality of the Universe's existence lay in the power of God to create it. On the atheistic hypothesis, there did not exist even the potentiality for the existence of the Universe. But then it seems inconceivable that the Universe should come to be actual if there did not exist any potentiality for its existence. Therefore, it seems that a cause of the Universe must exist.

Of course, as Grünbaum reminds us, it is an empirical question as to whether classical Big Bang cosmogeny is a realistic account of the origin of the Universe. But current doubts about the cold, dark matter model of the formation of the large-scale structure of the Universe do not call into question the Big Bang itself, nor have alternative models, whether quantum $^{2}$ or plasma ${ }^{3}$ yet turned out to be convincing. Therefore, it seems to me that, like it or not, currently accepted cosmological theory does lend tangible support to the theistic doctrine of creatio ex nihilo.

WILLIAM LANE CRAIG ur de Philosophie, Université Catholique de Louvain, Avenue des rouges gorges 8 , 1950 Kraainem. Belgium

1. Grünbaum, A. Nature 344, 821-822 (1990) 2. Craig, W. L. Brit. J. Phit Sci. 41, 473-491 (1990) 3. Kevles, D. J. NY Rev. Books 31 (16 May 1991)

\section{Just screening}

SIR - It is good that some of the ethical issues in science are being discussed in Nature, but the quality of the ethical arguments, or statements, is sometimes deficient.

A recent article (Nature 351, 591; 1991) states that "a rule that insurance companies should not seek genetic information about potential policy-holders would be unjust to those free from defect". Why is it unjust for the "healthy" to support the treatment of the sick?

The use of the expression "free of defect" is indirectly to call the genetically sick "defective", which is not the language we should find in Nature. A later editorial comment correctly points out that everyone contains many misfunctional alleles, and all people have some "defects" or "abnormality" (Nature 352, $11-14 ; 1991)$, yet even that still begs the question why people relatively free from identifiable genetic "abnormality" should pay for the care of the sick.

That view goes against the widely accepted ideas of justice in society. Justice requires society to support the sick, the disadvantaged and all those who need help, because of "accidents" of either nature or nurture. A widely accepted theory of justice would have it that a just society is one whose principles we would all accept if we did not know in advance what position, or state of health, we would have in it $^{1}$. It is not unjust for the healthy to support the sick to a reasonable standard of care, but it is unjust to the sick to discriminate against them.

DARRYL MACER

Institute of Biological Sciences,

University of Tsukuba.

Ibaraki 305, Japan

1. Rawls, J. A Theory of Justice (Harvard University Press. Boston, 1972)

Nature's line is that the care of the disadvantaged, genetically or otherwise, is a public responsibility that cannot be met by the regulation of private insurance companies. - Editor, Nature. 